\title{
Effects of mechanical strain on periodontal ligament fibroblasts in presence of Aggregatibacter actinomycetemcomitans lysate
}

Agnes Schröder ${ }^{* *}$, Julia Stumpf ${ }^{1}$, Eva Paddenberg ${ }^{1}$, Patrick Neubert ${ }^{2}$, Valentin Schatz ${ }^{2}$, Josef Köstler ${ }^{2}$, Jonathan Jantsch ${ }^{2}$, James Deschner ${ }^{3}$, Peter Proff ${ }^{1}$ and Christian Kirschneck ${ }^{1}$

\begin{abstract}
Purpose: Many adult orthodontic patients suffer from periodontitis, which is caused by oral pathogens such as the gram-negative Aggregatibacter actinomycetemcomitans (Agac). Like orthodontic tooth movement, periodontitis is associated with inflammation and alveolar bone remodelling thereby affecting orthodontic treatment. Interactions of both processes, however, are not sufficiently explored, particularly with regard to oxidative stress.

Methods: After preincubation with Agac lysate for $24 \mathrm{~h}$ periodontal ligament fibroblasts (PDLF) were either stretched or compressed for further $48 \mathrm{~h}$ simulating orthodontic forces in vitro. We analysed the expression of genes and proteins involved in the formation of reactive oxygen species (NOX-4, ROS) and nitric oxide (NOS-2), inflammation (TNF, IL-6, PTGS-2) and bone remodelling (OPG, RANKL).

Results: Agac lysate elevated the expression of NOX-4, NOS-2, inflammatory IL-6 and PTGS-2 and the bone-remodelling RANKL/OPG ratio during compressive, but not tensile mechanical strain. Agac lysate stimulated pressure-induced inflammatory signalling, whereas surprisingly ROS formation was reduced. Pressure-induced downregulation of OPG expression was inhibited by Agac lysate.
\end{abstract}

Conclusions: Agac lysate impact on the expression of genes and proteins involved in inflammation and bone remodelling as well as ROS formation, when PDLF were subjected to mechanical forces occurring during orthodontic tooth movement.

Keywords: Periodontal ligament fibroblast, PDL, Orthodontic tooth movement, Periodontitis, Inflammation

\section{Introduction}

Orthodontic treatment prevents and corrects dysfunctions, malocclusions and jaw malposition. In addition to essential skills like speaking or chewing, oral health is considered an essential foundation of holistic health

\footnotetext{
*Correspondence: agnes.schroeder@ukr.de

1 Department of Orthodontics, University Hospital Regensburg,

Regensburg, Germany

Full list of author information is available at the end of the article
}

including physical and mental well-being, contributing to the quality of life $[1,2]$. Oral diseases are one of the most common public health conditions and remain a major global health burden [2]. Among these, dental caries and periodontal disease are cited by the WHO (world health organization) as the most important oral health burdens worldwide [3, 4]. Increased plaque accumulation favours the development of pathogenic processes in the periodontium and is associated with gingivitis and also periodontitis [5]. Periodontitis is characterised by a bacterial 
inflammatory pathophysiological breakdown of periodontal tissue with irreversible bone loss [6]. Therefore it has the potential to interfere with orthodontic therapy. An uncontrolled inflammatory process during orthodontic treatment in a periodontally challenged dentition can result in orthodontically induced root resorption, including destruction of the periodontal tissue [7]. In contrast to the pathophysiological inflammation and destruction of periodontal tissue that can be detected as signs and symptoms of periodontitis [6, 8], a local so-called controlled sterile inflammatory cascade is activated during orthodontic tooth movement inducing bone remodelling $[7,9]$. During orthodontic treatment, cells in the periodontal ligament are subjected to compressive and tensile strain $[7,9,10]$, resulting in bone deposition by osteoblasts at tension and bone resorption by osteoclasts at pressure areas [11]. Osteoclastogenesis is controlled by the expression of receptor activator of NF-kB ligand (RANKL) and its decoy receptor osteoprotegerin (OPG) [12]. Next to osteoblasts, periodontal ligament fibroblasts (PDLF) can express both genes and thereby modulate differentiation of precursor cells to bone-resorbing osteoclasts in response to mechanical stress $[10,13]$. In a healthy periodontal condition, orthodontic treatment does not induce gingival recessions, alveolar bone loss or increased pocket depths to a clinically relevant extent [14], whereas this is true for orthodontic treatment during active periodontitis [15].

Periodontitis is a complex clinical entity, determined by the nature of the biofilm, individual risk factors and host defence [16]. In this respect, the importance of bacterial colonisation for the planning and implementation of orthodontic therapy cannot be neglected and of clinical relevance due to the increasing number of adult orthodontic treatments [17]. The gram-negative periodontal pathogens, Aggregatibacter actinomycetemcomitans (A. actinomycetemcomitans, Agac) and Porphyromonas gingivalis ( $P$. gingivalis) possess virulence factors, which can activate neutrophil granulocytes, macrophages and fibroblasts [6]. When stimulated with the lipopolysaccharide of $P$. gingivalis and $A$. actinomycetemcomitans, human PDLF showed a significantly increased expression of proinflammatory cytokines such as IL-6 and TNF [18]. As similar effects occur during orthodontic force application [10], it can be assumed that bacterial stress may influence orthodontic treatment. Reactive oxygen and nitrogen species (ROS/RNS) are increasingly generated by neutrophil granulocytes and fibroblasts in the course of inflammatory processes such as periodontitis [19]. In addition, reactive oxygen metabolites and nitric oxide are produced by macrophages and neutrophil granulocytes to defend against bacteria and kill germs [20]. As ROS are also produced intracellularly under oxygen-deficient conditions during different enzymatically modulated reactions, it is conceivable that hypoxia occurring during tooth movement [21] could stimulate PDLF to produce ROS. The key interacting enzyme in the so-called oxidative burst, NADPH oxidase (NOX), forms large amounts of ROS [22]. The objective of this study was thus to determine the effects of $A$. actinomycetemcomitans (Agac) lysate on the expression of inflammatory and boneremodelling genes in PDLF during mechanical loading, in particular with regard to ROS production.

\section{Material and methods}

\section{Isolation of human periodontal ligament fibroblasts}

For the experiments we pooled periodontal ligament fibroblasts (PDLF) from six individual patients (three males, three females) aged 17-27 years. Isolation of periodontal tissue from intact third molars without any carious lesions after extraction for medical reasons and the subsequent experiments were approved by the ethics committee of the University of Regensburg, Germany (Approval Number 12-170-0150). Informed written consent was obtained from the subjects. To isolate PDLF, periodontal ligament was removed from the middle third of the tooth root under sterile conditions and transferred to $5 \mathrm{ml}$ sterile PBS (14190094, Life Technologies) containing $1 \%$ antibiotic/antimycotic (AA, with 10,000 units/ $\mathrm{ml}$ penicillin, $10 \mathrm{mg} / \mathrm{ml}$ streptomycin and $25 \mu \mathrm{g} / \mathrm{ml}$ amphotericin B; A5955, Sigma-Aldrich). After addition of $8 \mu \mathrm{l}$ collagenase type II $(\sim 160 \mathrm{U} / \mathrm{ml} ; 17101-015$, Thermo Fisher Scientific), the periodontal ligament was incubated for $20 \mathrm{~min}$ at $37^{\circ} \mathrm{C}$. The supernatant was removed, the isolated tissue washed again with sterile $\mathrm{PBS}+\mathrm{AA}$ and the tissue pieces were placed in 6-well cell culture plates (353046, Omnilab/BD) containing 2 ml DMEM High Glucose (D5671, Sigma-Aldrich) with 10\% fetal bovine serum (FBS, P30-3302, PAN-Biotech), 1\% AA (A5955, Sigma-Aldrich); 1\% L-glutamine (G7513, Sigma-Aldrich) per well and cultured under cell culture conditions until fibroblasts grew out (Additional file 1: Figure S1).

\section{In vitro cell culture experiments}

For experiments, we seeded 70,000 PDLF up to the sixth passage either on polystyrol plates (353046, BD Bioscience) for pressure application or on collagen-coated bioflex plates (BF-3001C, Dunn Labortechnik) for tensile strain in DMEM High Glucose (D5671, Sigma Aldrich), supplemented with 10\% FBS (P30-3302, PAN Biotech), 1\% AA (A5955, Sigma Aldrich), 1\% L-glutamine (G7513, Sigma Aldrich) and 1\% ascorbic acid (B6891, Sigma Aldrich). We either left the cells untreated or added $200 \mu \mathrm{l}$ A. actinomycetemcomitans (Agac) lysate for $24 \mathrm{~h}$ [23]. After that we compressed PDLF with a sterile glass plate $\left(2 \mathrm{~g} / \mathrm{cm}^{2}\right)$ [24] or stretched them using a spherical 
silicone stamp (16\%) [25] for another $48 \mathrm{~h}$ according to validated and published protocols without changing the cell culture medium.

\section{Preparation of Agac lysate}

Aggregatibacter actinomycetemcomitans (DSM 11123; provided by the German Collection of Microorganisms and Cell Cultures) was incubated anaerobically on sheep blood agar plates for $3-5$ days at $37^{\circ} \mathrm{C}$. A single colony was used to inoculate a brain-heart infusion broth (Carl Roth). When the bacteria attained post-logarithmic growth, they were harvested by centrifugation and concentrated to an optical density of 1 at $690 \mathrm{~nm}$ equivalent to $\approx 1 \times 10^{8}$ colony-forming units per $\mathrm{ml}$. The lysate was prepared by heating the suspension for $10 \mathrm{~min}$ at $60^{\circ} \mathrm{C}$.

\section{RNA isolation}

For RNA isolation, we vortexed PDLF in $500 \mu \mathrm{l}$ Trizol (30-2010, VWR) with $100 \mu \mathrm{l}$ chloroform (1.02445.1000, VWR) for $30 \mathrm{~s}$. After $15 \mathrm{~min}$ incubation on ice, the suspension was centrifuged at $13,000 \mathrm{rpm}$ for $15 \mathrm{~min}$ at $4{ }^{\circ} \mathrm{C}$ and the supernatant was mixed with $500 \mu \mathrm{l}$ of pre-cooled isopropanol (20.842.330, VWR). The samples were mixed by inverting and incubated overnight at $-80^{\circ} \mathrm{C}$. Samples were centrifuged at $13,000 \mathrm{rpm}$ at $4{ }^{\circ} \mathrm{C}$ for $30 \mathrm{~min}$ and washed twice with $80 \%$ ethanol (1.00983, Sigma-Aldrich). The pellet was dried for at least $30 \mathrm{~min}$ and resuspended in $20 \mu \mathrm{l}$ RNase-free water (T143.5, Carl Roth). The concentration of RNA was measured in the nano-photometer NP60 (Implen).

\section{CDNA synthesis}

To minimize variations, we prepared a master mix consisting of $200 \mathrm{U}$ M-MLV reverse transcriptase (M1705, Promega), $40 \mathrm{nmol} \mathrm{dNTPs} \mathrm{(L785.2,} \mathrm{Carl} \mathrm{Roth),} 0.1 \mathrm{nmol}$ Oligo (dT) 18-primer (SO132, Thermo Fisher), $0.1 \mathrm{nmol}$ random hexamer primer (SO142, Thermo Fisher), $40 \mathrm{U}$ RiboLock RNase Inhibitor (EO0382, Thermo Fisher) and
$1 \times$ M-MLV RT Buffer (M1705, Promega) and mixed the master-mix with equal amounts of RNA (100 ng). Samples were incubated at $37^{\circ} \mathrm{C}$ for $1 \mathrm{~h}$, followed by $95{ }^{\circ} \mathrm{C}$ for $2 \mathrm{~min}$ for transcriptase inactivation in a thermocycler (Doppio 2.48 well Block, VWR).

\section{Quantitative real-time polymerase chain reaction ( $R T-q P C R$ )}

To determine the relative expression of the examined genes, an individual primer mix containing $7.5 \mu \mathrm{l}$ SYBR $^{\circledR}$ Green JumpStart ${ }^{\mathrm{TM}}$ Taq ReadyMix ${ }^{\mathrm{TM}}$ (S4438, Sigma-Aldrich), the respective primer pair $(7.5 \mathrm{pmol}$, $0.75 \mu \mathrm{l}-3.75 \mathrm{pmol} / \mathrm{primer}$ ) and $5.25 \mu \mathrm{l}$ nuclease-free $\mathrm{H}_{2} \mathrm{O}$ (T143, Carl-Roth $\mathrm{GmbH}$ ) were mixed with $1.5 \mu \mathrm{l}$ cDNA per sample in a 96-well TW-MT plate (712282, Biozym). RT-qPCR was performed in a realplex2 master cycler (Eppendorf). The plates were heated to $95{ }^{\circ} \mathrm{C}$. for $5 \mathrm{~min}$ followed by 45 cycles at $95^{\circ} \mathrm{C}$ for $10 \mathrm{~s}$, at $60^{\circ} \mathrm{C}$ for $8 \mathrm{~s}$ and at $72{ }^{\circ} \mathrm{C}$ for $8 \mathrm{~s}$. For compression experiments we used a combination of PPIB/RPL22 [23] as reference genes for normalisation of target gene expression, while a combination of TBP/PPIB [25] was used for tensile strain experiments (Table 1). We determined the used reference gene combination as most stable reference combination for the tested setup based on mathematical algorithms.

Relative gene expression was calculated using the formula $2^{-\Delta \mathrm{Cq}}[26]$, where $\Delta \mathrm{Cq}$ was calculated from Cq (target gene) $-\mathrm{Cq}$ (geomean reference genes). It was then divided by the arithmetic mean of the control group in order to obtain a relative gene expression in relation to the control group.

\section{Protein isolation and determination of concentration}

For protein isolation PDLF were scraped off in $100 \mu \mathrm{l} \mathrm{Cel-}$ Lytic M (C2978, Sigma Aldrich) with protease inhibitors diluted 1:100 according to manufacturer's instructions (87786, Thermo Fisher) and placed on ice for $15 \mathrm{~min}$. Samples were centrifuged at $13,000 \mathrm{rpm}$ for $10 \mathrm{~min}$ at

Table 1 RT-qPCR primer sequences for reference genes (TBP, RPL22, PPIB) and target genes

\begin{tabular}{llll}
\hline Gene symbol & Gene name & $\mathbf{5}^{\prime}$-forward primer-3' & $\mathbf{5}^{\prime}$-reverse primer-3' \\
\hline PPIB & Peptidylprolyl isomerase A & TTCCATCGTGTAATCAAGGACTTC & GCTCACCGTAGATGCTCTTTC \\
RPL22 & Ribosomal protein L22 & TGATTGCACCCACCCTGTAG & GGTTCCCAGCTTTTCCGTTC \\
IL-6 & Interleukin-6 & TGGCAGAAAACAACCTGAACC & CCTCAAACTCCAAAAGACCAGTG \\
PTGS-2 & Prostaglandin-endoperoxide synthase-2 & GAGCAGGCAGATGAAATACCAGTC & TGTCACCATAGAGTGCTTCCAAC \\
TBP & TATA binding protein & CGGCTGTTTAACTTCGCTTCC & TGGGTTATCTTCACACGCCAAG \\
TNF & Tumor necrose factor & GAGGCCAAGCCCTGGTATG & CGGGCCGATTGATCTCAGC \\
OPG & Osteoprotegerin & TGTCTTTGGTCTCCTGCTAACTC & ACGCTCCAGGACTTATACCG \\
RANKL & Receptor activator of NFkB ligand & ATACCCTGATGAAAGGAGA & GGGGCTCAATCTATATCTCG \\
NOX-4 & NADPH oxidase 4 & TCTGCCTGTTCATCTGGCTCTCCA & AGCCAAGAGTGTCGGCACATGGGTA \\
\hline
\end{tabular}


$4{ }^{\circ} \mathrm{C}$. Protein concentration was determined with RotiQuant (K015.3, Carl Roth).

\section{Western Blot analysis}

Equal amounts of protein $(10 \mu \mathrm{g})$ were heated to $70{ }^{\circ} \mathrm{C}$ for 7 min with $1 \times$ loading buffer $(6 \times$ sample buffer: of $0.375 \mathrm{M}$ Tris $/ \mathrm{HCl} \mathrm{pH} 6.8,30 \%$ glycerol (3783.1, Carl Roth), 12\% SDS (8029.1, Carl Roth), 0.6\% bromophenol blue (T116.2, Carl Roth), 1\% dithiothreitol (6908.1, Carl Roth)). After centrifugation (7000 rpm for $7 \mathrm{~min}$ at $4{ }^{\circ} \mathrm{C}$ ), the samples were stored at $-80{ }^{\circ} \mathrm{C}$ for further use. Proteins were separated on polyacryl amid gels consisting of a $10 \%$ separation gel $\left(38 \% \mathrm{H}_{2} \mathrm{O}_{\mathrm{d}}, 34 \%\right.$ acrylamide mix/ rotiphoresis gel 30 (3029.1, Carl Roth), 26\% 1.5 M Tris/ $\mathrm{HCl}$ pH8.8, 1\% SDS (8029.1, Carl Roth), 1\% ammonium peroxide sulphate (9592.2 Carl Roth), 0.04\% TEMED (T9281, Sigma Aldrich)) and a collecting gel $\left(70 \% \mathrm{H}_{2} \mathrm{O}_{\mathrm{d}}\right.$, $16.5 \%$ acrylamide mix/rotiphoresis gel $30,12.5 \% 1.0 \mathrm{M}$ Tris/HCl pH6.8, 1\% SDS, 1\% APS and 0.1\% TEMED) using the Mini-PROTEAN Tetra Cell (1658005EDU, BIO-RAD) in $1 \times$ electrode buffer $(10 \times$ electrode buffer: $24.8 \mathrm{mM}$ Tris/Trizma base (T1503, Sigma Aldrich), 3.5 mM SDS (8029.1, Carl Roth), 1.9 M glycine (33226, Sigma-Aldrich)). Protein standard (5 $\mu \mathrm{l} ; 26,616$, Thermo Fisher) was pipetted onto each gel. The gels were first connected for $30 \mathrm{~min}$ at $80 \mathrm{~V}$, then left to run for $90 \mathrm{~min}$ at $120 \mathrm{~V}$. Afterwards, proteins were transferred onto a PVDF membrane (T830.1, Carl Roth) at $90 \mathrm{~V}$ for $90 \mathrm{~min}$ in $1 \times$ transfer buffer $(20 \times$ transfer buffer: $0.2 \mathrm{M}$ Tris/ Trizma base (T1503, Sigma Aldrich), 2 M glycine (33226, Sigma-Aldrich)) including 10\% methanol using a tankblot apparature (1660827EDU, BIO-RAD). The membrane was blocked for $1 \mathrm{~h}$ at RT in 5\% milk (T145.3, Carl Roth) in TBS-T. The membranes were incubated over night at $4{ }^{\circ} \mathrm{C}$ (NOS-2: 1:2000, PA3-030A, invitrogen; NOX4: 1:2000; PA5-88106, invitrogen; ACTIN: 1:3000, ABIN 274248, antibody-online) in 5\% milk (T145.3, Carl Roth) in TBS-T with agitation. After washing three times in TBS-T, membranes were incubated with the secondary antibody (1:5000: 611-1302, RockLand) in 5\% milk in TBS-T for $1 \mathrm{~h}$ at room temperature. After washing three times, the membrane was covered with Luminata Crescendo (WBLUR0100, Sigma-Aldrich) and the signal was detected with VWR Genoplex. Densitometric analysis was performed with Image J (NIH, US). To test antibodies, the membrane was stripped. After development the membrane was first washed three times for $10 \mathrm{~min}$ at RT on the shaker and then incubated for $20 \mathrm{~min}$ on the shaker in a solution consisting of Re-Blot Plus Mild $(10 \times)(2502$, Merck) diluted with TBS in a ratio of 1:10. The TBS solution was composed of $100 \mathrm{ml} 10 \times$ TBS and $900 \mathrm{ml}$ distilled water. Before the membrane was incubated with another primary antibody, the membrane was washed twice for $10 \mathrm{~min}$ in TBS-T and blocked for $1 \mathrm{~h}$ in $5 \%$ milk in TBS-T.

\section{FACS analysis}

For measurement of reactive oxygen species (ROS), we performed FACS analysis. Therefore we seeded PDLF in DMEM high glucose (D5671, Sigma Aldrich), supplemented with 10\% FBS (P30-3302, PAN Biotech), 1\% AA (A5955, Sigma Aldrich), 1\% L-glutamine (G7513, Sigma Aldrich) and 1\% ascorbic acid (B6891, Sigma Aldrich). PDLF were stained with chloromethyl-H2DCFDA (C6827, Thermo Fisher) $5.5 \mathrm{~h}$ after pressure application. For this purpose, the dye was dissolved in $44.4 \mu \mathrm{l}$ DMSO (A994.1, Carl Roth) according to the manufacturer's instructions and $2 \mu \mathrm{l}$ were pipetted into each well (final dilution $0.1 \%$ ). After six hours of compressive force treatment, cell culture supernatant was removed and PDLF were solved with $500 \mu \mathrm{l} 0.25 \%$ trypsin/EDTA (T4049, Sigma-Aldrich) per well and transferred to FACS tubes. PDLF from three wells were pooled for analysis. Cells were centrifuged at $300 \mathrm{~g}, 4{ }^{\circ} \mathrm{C}$ for $5 \mathrm{~min}$ and the supernatant was discarded. After adding $3 \mathrm{ml}$ of PBS, the tubes were centrifuged again with the same settings, the supernatant was discarded and $200 \mu \mathrm{l}$ of PBS were pipetted onto the cell pellet. Finally, the cell suspension was vortexed and measured with the BD FACSCanto II with a $488 \mathrm{~nm}$ solid state 20-mM laser (BD Biosciences; excitation/emission: 492-495/517-527 nm). Gating strategy is presented as Additional file 1: Figure S3.

\section{Statistical methods}

Symbols represent individual measurements, the horizontal line represents the calculated mean and the vertical line shows the standard error. Statistical evaluation was carried out with GraphPad Prism Version 9.0 (GraphPad software). Normal distribution of the data was first checked using the Shapiro-Wilk test and homogeneity of variance with Levene's test. Either a Welchcorrected ANOVA with Games-Howell post hoc tests in case of a violation of requirements for parametric testing or an ANOVA with a subsequent Holm-Sidak's post hoc tests was then carried out. Differences were rated as statistically significant at $p \leq 0.05$.

\section{Results}

Impact of Agac lysate and tensile strain on protein expression of NADPH oxidase-4 (NOX-4) and nitric oxide synthase-2 (NOS-2)

After assessment of cell number and lactate dehydrogenase (LDH) release, which revealed a cytotoxic effect of Agac lysate and mechanical strain (Additional file 1: Figure S2), we investigated the effects of Agac lysate in combination with tensile strain on protein expression of 
NOX-4 and NOS-2. Tensile strain alone had no effect on NOX-4 mRNA ( $p=0.282$; Fig. 1a) and protein expression $(p=0.964 ;$ Fig. 1b). Additional treatment with Agac lysate, however, increased NOX-4 expression significantly without tensile strain on mRNA level $(p=0.008$; Fig. 1a) and with tensile strain on protein level $(p=0.05$; Fig. 1b). Like NOX-4, NOS-2 protein expression was upregulated significantly with Agac lysate in combination with tensile strain in PDLF ( $p=0.004$; Fig. $1 \mathrm{c})$.

\section{Impact of Agac lysate and tensile strain on expression of inflammatory genes}

Next, we investigated the effect of Agac lysate and tensile strain on the gene expression of the inflammatory genes tumor necrose factor (TNF), interleukin-6 (IL-6) and prostaglandin-endoperoxide synthase-2 (PTGS-2). $T N F$ gene expression was upregulated after tensile strain without Agac treatment ( $p=0.020$; Fig. 2a). Surprisingly, the effect of tensile strain was inhibited in PDLF treated with Agac lysate $(p=0.707)$. Agac lysate without tensile strain had no effect on TNF gene expression compared to the control group without Agac and without tensile strain ( $p=0.798$; Fig. 2a). In contrast to $T N F, I L-6$ gene expression was reduced with tensile strain in PDLF without Agac lysate ( $p=0.007$; Fig. 2b). Treatment with Agac lysate increased $I L-6$ gene expression without $(p=0.006)$ and with tensile strain $(p=0.014)$ compared to PDLF with no Agac treatment (Fig. 2b). Tension elevated
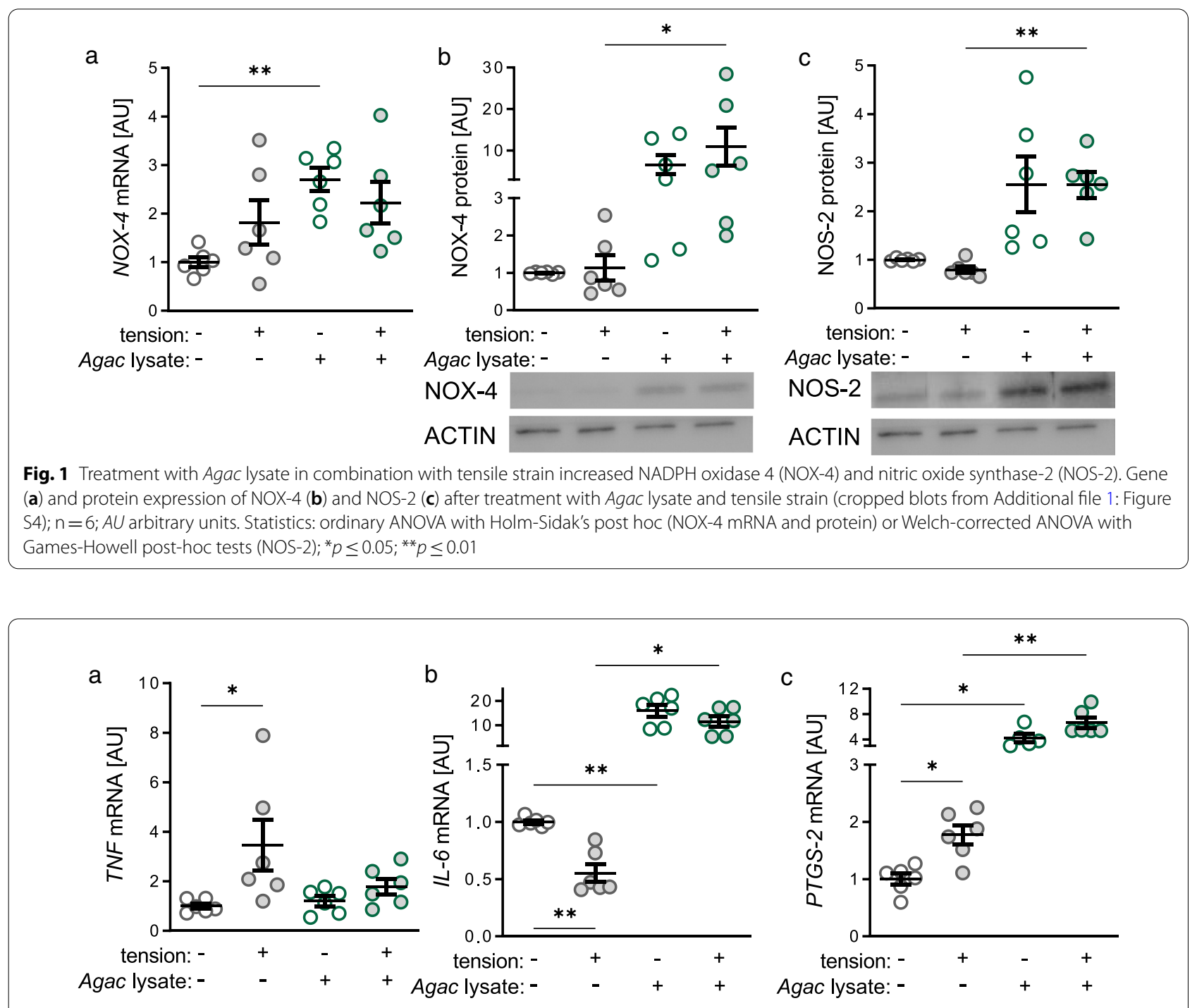

Fig. 2 Agac lysate increased gene expression of interleukin-6 (IL-6) and prostaglandin-endoperoxide synthase-2 (PTGS-2). Gene expression of tumor necrose factor (a TNF), IL-6 (b) and PTGS-2 (c) after treatment with Agac lysate and tensile strain; $n \geq 5 ; A U$ arbitrary units. Statistics: ordinary ANOVA with Holm-Sidak's post hoc (TNF) or Welch-corrected ANOVA with Games-Howell post-hoc tests (IL-6, PTGS-2); ${ }^{*} p \leq 0.05 ;{ }^{* *} p \leq 0.01 ;{ }^{* * *} p \leq 0.001$ 
PTGS-2 gene expression $(p=0.019)$ under control conditions without Agac (Fig. 2c). With Agac lysate PTGS-2 gene expression was increased without $(p=0.026)$ and with tension $(p=0.006)$ compared to untreated PDLF, while the observed effect of tensile strain was abolished $(p=0.171$; Fig. 2c).

\section{Impact of Agac lysate and tensile strain on expression of bone remodelling genes}

Neither treatment with Agac lysate $(p=0.494)$ nor tensile strain $(p=0.438)$ impacted on $R A N K L$ gene expression (Fig. 3a). OPG gene expression was also not significantly affected by any tested condition ( $p \geq 0.234$; Fig. $3 b)$. This resulted in an unchanged $R A N K L / O P G$ ratio after Agac lysate treatment without mechanical strain or after tensile strain $(p \geq 0.422$; Fig. 3c).

\section{Impact of Agac lysate and compression on protein} expression of NADPH oxidase-4 (NOX-4) and nitric oxide synthase-2 (NOS-2)

Pressure application increased NOX-4 gene expression without $(p=0.004)$ and with $\operatorname{Agac}$ lysate $(p=0.004$; Fig. 4a). Agac lysate had no effect on NOX-4 gene expression under control conditions $(p=0.788)$ and with compressive strain $(p=0.788)$. NOX-4 protein expression was elevated with pressure at control conditions $(p=0.003$; Fig. 4b). Agac lysate increased NOX-4 protein expression without $(p<0.001)$ and with compressive strain $(p<0.001)$ compared to control conditions. The effect of pressure application on NOX-4 protein expression was abolished with Agac lysate ( $p=0.259$; Fig. $4 \mathrm{~b})$. Under control conditions, pressure application increased ROS development in PDLF ( $p=0.019$; Fig. $4 \mathrm{c}$ and Additional file 1: Figure S3). Surprisingly, Agac lysate truncated this pressure-induced effect $(p=0.008)$. NOS-2 protein expression was elevated with mechanical strain under control conditions $(p=0.008)$ and after addition of Agac lysate $(p=0.015$; Fig. $4 \mathrm{~d})$ without pressure application. With Agac lysate, the pressure effect was no longer detectable $(p=0.890)$.

\section{Impact of Agac lysate and compression on expression of inflammatory genes}

Under control conditions pressure application $(p=0.791)$ or Agac lysate treatment $(p=0.791)$ did not significantly impact on TNF gene expression (Fig. 5a). However, a combination of mechanical strain with Agac lysate elevated TNF gene expression significantly compared to compressive force without Agac $(p<0.001)$ or Agac lysate without pressure application $(p<0.001$; Fig. $5 \mathrm{a})$. In contrast, $I L-6$ gene expression was increased with compression both without $(p<0.001)$ and with Agac lysate $(p=0.049$; Fig. 5b). Treatment with Agac lysate elevated IL-6 gene expression under control conditions $(p=0.005)$ and with pressure application ( $p=0.007$; Fig. $5 \mathrm{~b})$. Similarly, we observed upregulated PTGS-2 gene expression after mechanical strain without $(p=0.007)$ and with Agac lysate $(p<0.001$; Fig. 5c). Addition of Agac lysate increased PTGS-2 gene expression without $(p=0.041)$ and with compressive force treatment $(p=0.001)$ compared to control conditions without Agac lysate (Fig. 5c), indicating a boosted inflammatory answer of PDLF to compressive force with Agac lysate.

\section{Impact of Agac lysate and compression on expression of bone remodelling genes}

For bone remodelling genes, we observed elevated RANKL gene expression after compressive force treatment without $(p=0.038)$ and with Agac lysate $(p=0.038$; Fig. 6a). Treatment with Agac lysate increased RANKL

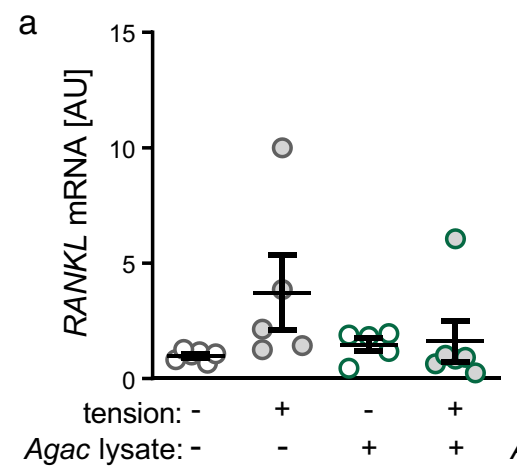

Fig. 3 Agac lysate in combination with tensile strain did not impact on expression of bone remodelling genes. Gene expression of receptor of NFk-B ligand (a RANKL), osteoprotegerin (b $O P G$ ) and RANKL/OPG ratio (c) after treatment with Agac lysate and tensile strain; $\mathrm{n}=6$; $A U$ arbitrary units. Statistics: ordinary ANOVA with Holm-Sidak's post hoc (RANKL, OPG) or Welch-corrected ANOVA with Games-Howell post-hoc tests (RANKL/OPG ratio) 

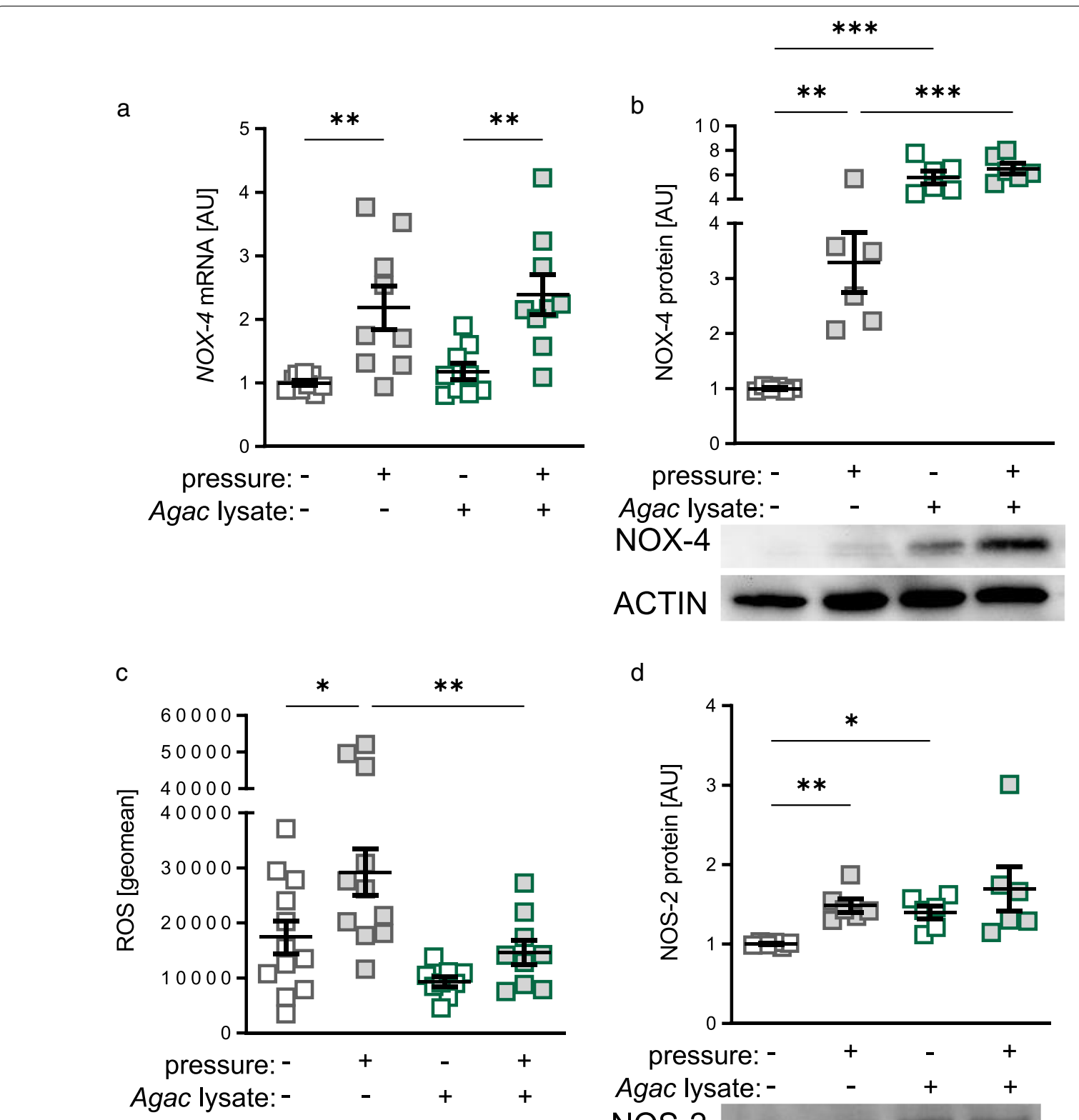

d

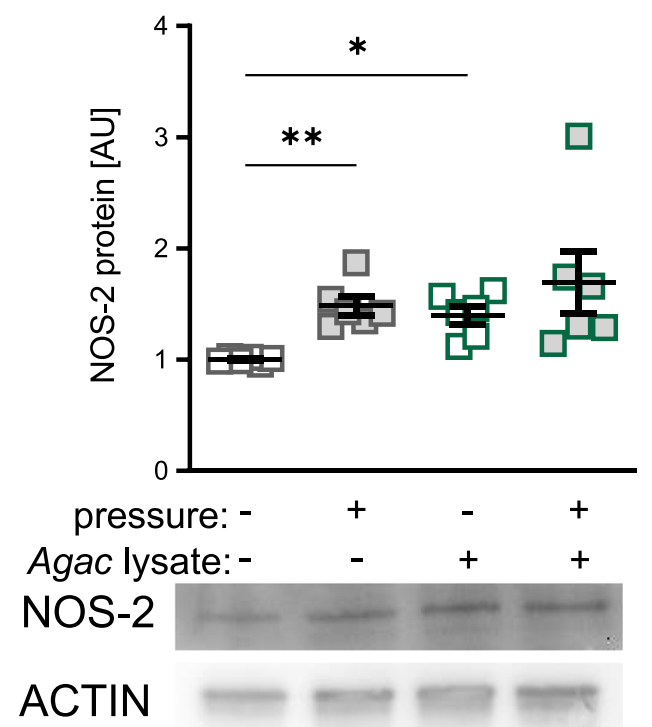

Fig. 4 Impact of Agac lysate in combination with compressive strain on development of reactive oxygen species (ROS) and expression of nitric oxide synthase-2 (NOS-2). Gene (a) and protein expression of NADPH oxidase-4 (b NOX-4), development of ROS (c) and NOS-2 (d) after treatment with Agac lysate and compressive strain (cropped blots from Additional file 1: Figure S5); $n \geq 6$; $A U$ arbitrary units. Statistics: ordinary ANOVA with Holm-Sidak's post hoc or Welch-corrected ANOVA with Games-Howell post-hoc tests (NOS-2); ${ }^{*} p \leq 0.05 ;{ }^{* *} p \leq 0.01 ;{ }^{* * *} p \leq 0.001$

gene expression without pressure $(p=0.001)$ and with compression $(p<0.001$; Fig. 6a). Surprisingly, Agac lysate also increased $O P G$ expression with compressive force treatment $(p=0.004)$, while pressure application alone failed to significantly impact on $O P G$ gene expression ( $p=0.158$; Fig. $6 \mathrm{~b})$. As a result, $R A N K L / O P G$ ratio increased significantly as expected with pressure application under control conditions ( $p=0.026$; Fig. 6c). Without pressure application, Agac lysate upregulated $R A N K L / O P G$ ratio $(p=0.008)$, while we detected no significant changes with Agac lysate combined with mechanical strain $(p=0.252)$ compared to pressure 

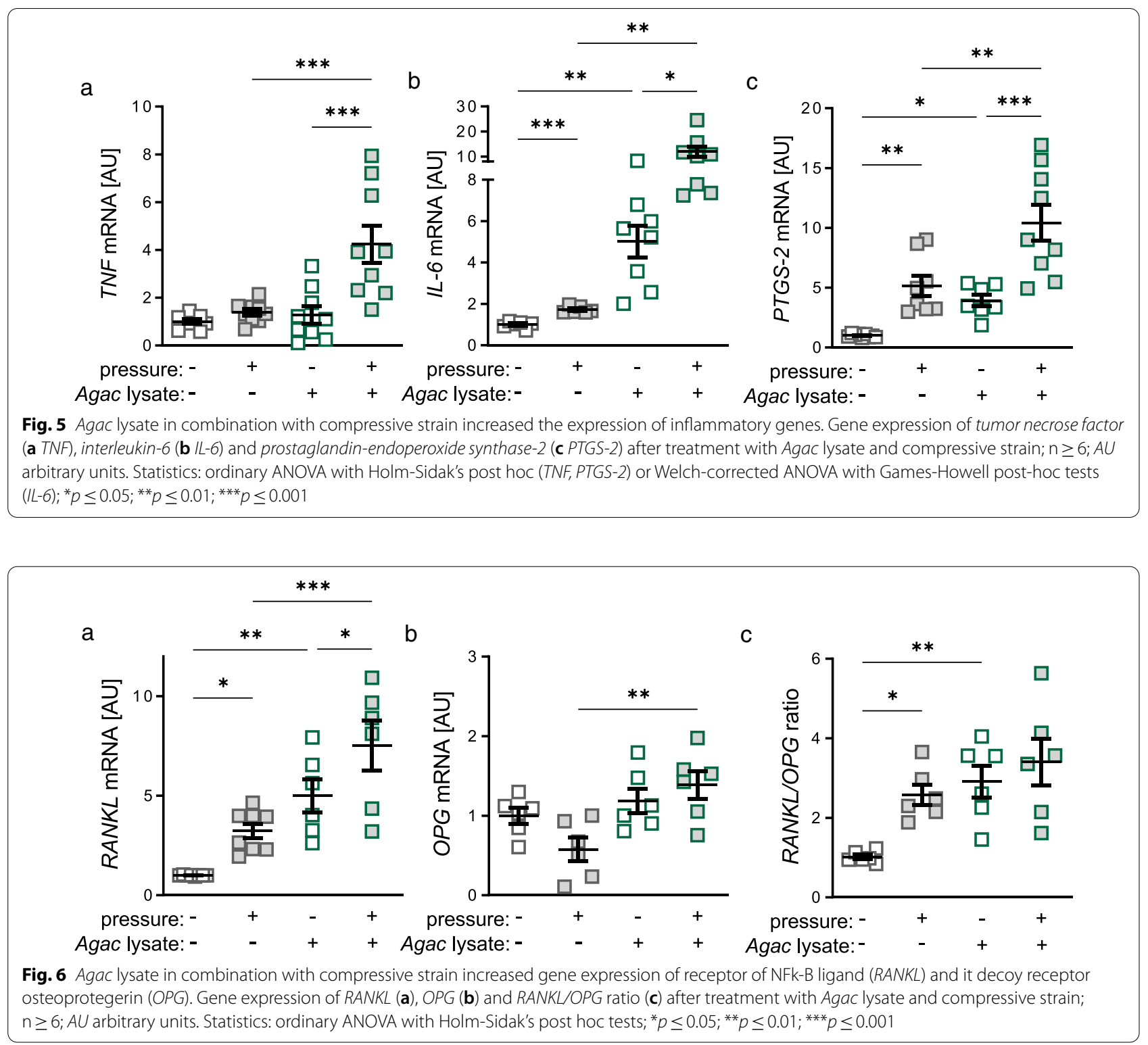

without Agac treatment (Fig. 6c). This data indicate, that Agac lysate impact on bone-remodelling genes by increasing $R A N K L$ expression, thereby eventually stimulating bone resorption.

\section{Discussion}

The aim of this work was to elucidate the influence of mechanical compression or isotropic stretching on the expression of inflammatory and bone-remodelling genes in PDLF during mechanical loading, in particular with regard to the development of reactive oxygen species (ROS) and nitric oxide in the presence of lysate of the periodontal pathogen Aggregatibacter actinomycetemcomitans (A. actinomycetemcomitans, Agac). Our results imply that biomechanical stress is a crucial factor in the regulation of cytokine production and that different inflammatory mediators respond differently to mechanical strain with a potentiating effect by Agac lysate.

Various cell populations are contained within the periodontal ligament including fibroblasts, monocytes and macrophages, $\mathrm{T}$ cells [27], undifferentiated mesenchymal cells, osteoblasts, osteoclasts and cementoblasts [28], which were subjected to mechanical stress induced by orthodontic treatment. PDLF, which comprise the majority of cells in the periodontal ligament, act as key players during orthodontic tooth movement $[9,10]$. At the molecular level, the cells in the periodontal ligament react to mechanical stress with a release of prostaglandins and 
cytokines, which determine the activity of bone cells [29]. Within the compression areas, the release of inflammatory cytokines such as interleukin-6 (IL-6) and tumour necrosis factor (TNF) [7, 30], the upregulation of prostaglandin-endoperoxide synthase-2 (PTGS-2) as a key enzyme of prostaglandin synthesis [7, 24, 29, 29, 31-33], as well as enhanced nitric oxide generation by NOS-2 [7] by PDLF ultimately trigger the secretion of receptor activator of NF-kB ligand (RANKL) and thus promote osteoclastogenesis $[29,31]$. Osteoprotegerin (OPG) acts as an antagonist of RANKL and counteracts osteoclastogenesis [34]. All the described processes apply to a healthy state of the dentition. However, pathological processes in the periodontally challenged dentition create altered conditions that must be taken into account in the context of orthodontic treatment.

The application of orthodontic forces initiates a sterile inflammation in the periodontium [9]. One of the first reactions to mechanical strain is an increased prostaglandin synthesis [31]. PTGS-2 was significantly upregulated by under pressure and stretch conditions. Agac lysate provided an additional potentiation of this effect. The production of proinflammatory cytokines by PDLF under mechanical compression is already regulated in the early phase of orthodontically induced tooth movement [24]. In agreement with results of previous in vitro studies, pressure conditions upregulated PTGS-2 by PDLF with enhanced effects under pre-stimulation with Agac lysate $[35,36]$. In contrast, an upregulation of gene expression could only be observed for $I L-6$ after compression, but not after tensile strain [25]. However, a bacterial stress factor leads to a higher gene expression of $I L-6$ for both forms of force application. While the gene expression of $I L-6$ and PTGS-2 in PDLF is dependent on the duration of mechanical compression, a comparable effect seems to occur for TNF only in combination with Agac lysate and under stretching conditions alone. Although a significant enhancing effect was observed in the stretch control, the bacterial lysate did not appear to potentiate the expression of TNF in stretched PDLF. Agac even showed tendencies to suppress the gene expression of $T N F$ after tensile strain. Although some studies point to an increased synthesis of TNF in orthodontic compression and tensile zones as an initiator of the local inflammatory response in vivo [37-39], our gene expression results showed only an upregulation in response to tensile strain. Stimulation with Agac lysate increased gene expression of TNF in PDLF after compression. Based on the fact that $T N F$ gene expression was significantly upregulated in macrophages after pressure application [40], our results suggest that TNF gene expression might be increased at an earlier point in time. Another possible explanation would be that TNF synthesis is up- and down-regulated in a species-specific manner. This hypothesis is supported by different TNF levels measured in gingival sulcus fluid in humans [41] and unchanged mRNA levels in animal experiments [30]. The joint upregulation of $I L-6$ and $R A N K L$ by PDLF under static compression suggests the induction of boneresorbing processes in the orthodontic pressure zone. During orthodontic tooth movement, increased RANKL and decreased OPG levels have already been detected in adult gingival sulcus fluid and in response to static compression in vitro, but with unchanged protein data [42]. Another in vitro study reported upregulated RANKL levels with pressure conditions, however, as in the present work, without downregulation of OPG, which was attributed to the heterogeneity of the periodontal ligament [31]. Increased catabolic dynamics at orthodontic compression zones were previously corroborated in vivo via RANKL upregulation [38] and are consistent with our results. Contrary to previous results [43], RANKL gene expression was not downregulated after tensile strain in this study. In another recent study, the authors observed a trend for increased $R A N K L$ gene expression which was then associated with a reduced RANKL secretion [44]. Interestingly, the bacterial stimuli showed opposite tendencies on bone metabolism. In an acute inflammatory stage, such as periodontitis or during the early phase of orthodontic tooth movement, RANKL is not synthesised exclusively by osteoblasts but mainly by immune cells and PDLF [9]. The potentiation of the bone-resorbing effects under static compression by stimulus in the form of Agac lysate indicate an enhancement of bone resorption. Based on the results regarding the RANKL/OPG ratio, it can therefore be assumed that tooth movement in the periodontally damaged dentition, imitated by the presence of Agac lysate, can promote bone-degrading mechanisms. Nitric oxide is considered an early modulator of adaptive bone remodelling processes under mechanical strain [45] and plays a mediating role in bone resorption via influencing osteoclast activity [46]. PDLF responded with an increased protein level of NOS-2 under Agac stimulus in combination with compression and a potentiating effect of both stimuli in the tensile group. The results suggest that stretched PDLF are stimulated to produce nitric oxide in response to the bacterial stimulus, while static compression emerges even as a stronger physical stressor to induce NOS-2. NOS-2 thus appears to play a role in both compressive and tensile zones of the periodontal ligament during orthodontic tooth movement, as measured by the in vitro model presented here. The role of nitric oxide as an instrument of host response and its effects on bone metabolism have been controversially discussed by Bast et al. [47]. Thus, both stimulatory-destructive and inhibitory-protective 
associations exist with increased bone loss after experimentally simulated periodontitis induced by infection with periodontal pathogens $[48,49]$. Bone metabolism and inflammatory status can also be influenced by ROS [47]. Elevated levels of ROS are involved in the pathogenesis of most inflammatory diseases [50, 51]. Oxidative stress can arise via many different pathways in the human organism and can be attributed to local or systemic factors during orthodontic tooth movement. These include inflamed periodontal condition [52] and aseptic inflammation in the periodontal ligament as a result of mechanical force application [53]. A comparison of these study results with those of the present work leads to the assumption that application of an orthodontic force can be considered the main inducer of oxidative stress in the periodontal ligament during the early phase of orthodontic tooth movement. Contrary to previous assumptions, the quantitative measurement of intracellularly formed ROS by PDLF did not indicate an increased response to the bacterial stimuli. Since high ROS concentrations can lead to apoptosis of gingival fibroblasts [50], it cannot be ruled out that the amount of ROS produced by PDLF independently led to a lower production of reactive oxygen species. Nevertheless, the results of the ROS measurement suggest that significantly higher ROS generation can be initiated by PDLF within compression zones after application of an orthodontic force. In a study by Nguyen et al. (2019), the presence of $P$. gingivalis lysate resulted in significant upregulation of oxidative stress biomarkers and superoxide anions in PDLF [54]. However, no higher ROS levels could be detected towards the lysate [54]. The significantly decreased levels of ROS under bacterial stimulation could be due to antioxidant protective mechanisms of PDLF. Thus, it is possible that a simultaneous endogenous activation of antioxidant enzymes in vitro in the form of superoxide dismutase, upregulation of catalase or increased activity of glutathione peroxidase [53,55] could have neutralised the resulting reactive oxygen metabolites. This study implies several limitations that should be mentioned. Due to the use of different plates with different surface coatings for performing experiments with compressive or tensile strain, comparisons between these experiments should be done with caution and are not intended. Furthermore, this could also explain different reaction patterns of PDLF on Agac lysate without mechanical strain. Expression profile of PDLF after treatment with Agac lysate and mechanical loading was mostly investigated at the mRNA level, which does not necessarily correspond to the protein level. The main limitation, however, is that the study is an in vitro study, only analysing one cell type of the periodontal ligament and the lysate of only one periodontitisrelated bacterium (Additional file 2).

\section{Conclusions}

The impact of Agac lysate on inflammatory (IL6, PTGS2, ROS, NOS2) and bone-remodelling factors (RANKL, OPG) was investigated in this study. We showed that Agac lysate impacts on the expression of genes and proteins involved in inflammation and bone remodelling as well as ROS formation, when PDLF were exposed to mechanical strain, as occurring during orthodontic tooth movement. Our results imply that the presence of Agac in periodontal lesions may have a potentiating effect on inflammation and bone resorption, if orthodontic therapy is performed, with progressive attachment and periodontal bone loss to be expected, if performing orthodontic tooth movement in presence of Agac. Further insights into how ROS interfere in oral health may contribute to understanding their role in orthodontic tooth movement based on the initiated local aseptic inflammatory response.

\section{Supplementary Information}

The online version contains supplementary material available at https://doi. org/10.1186/s12903-021-01761-3.

Additional file 1. Additional file presents (1) fibroblast growing out of periodontal ligament tissue, (2) cell number and lactatedehydrogenase release, (3) gating strategy for ROS FACS and uncropped western blots for figures 1 and $4(4,5)$.

Additional file 2. Numeric original data set for data presented in this study.

Acknowledgements

The authors thank Mrs. Eva Zaglauer for technical support.

Authors' contributions

Conceptualization, AS, PP, JD and CK; methodology, AS, PN, JJ and CK; validation, AS and CK; investigation, AS, JSPN and VS; resources, JK and PP; data curation, EP, VS and AS; writing —original draft preparation, AS and CK; writing - review and editing, EP, JD and PP; supervision, PP; project administration, $\mathrm{AS}$ and CK. All authors read and approved the final manuscript.

Funding

Open Access funding enabled and organized by Projekt DEAL.

Availability of data and materials

Datasets are available as additional file 2 .

\section{Declarations}

Ethics approval and consent to participate

Isolation of periodontal tissue from wisdom teeth after extraction for medical reasons was approved by the ethics committee of the University of Regensburg, Germany (Approval Number 12-170-0150). Informed written consent was obtained from the subjects. All methods were performed in accordance with relevant guidelines and regulations and the Declaration of Helsinki.

\section{Consent for publication}

Not applicable.

Competing interests

The authors declare that they have no competing interests. 


\section{Author details}

${ }^{1}$ Department of Orthodontics, University Hospital Regensburg, Regensburg, Germany. ${ }^{2}$ Institute of Clinical Microbiology and Hygiene, University Hospital Regensburg, Regensburg, Germany. ${ }^{3}$ Department of Periodontology and Operative Medicine, University Medicine Mainz, 55131 Mainz, Germany.

Received: 7 April 2021 Accepted: 4 August 2021

Published online: 18 August 2021

\section{References}

1. Glick M, Williams DM, Kleinman DV, Vujicic M, Watt RG, Weyant RJ. A new definition for oral health developed by the FDI World Dental Federation opens the door to a universal definition of oral health. J Public Health Dent. 2017;77:3-5. https://doi.org/10.1111/jphd.12213.

2. Jin LJ, Lamster IB, Greenspan JS, Pitts NB, Scully C, Warnakulasuriya S. Global burden of oral diseases: emerging concepts, management and interplay with systemic health. Oral Dis. 2016;22:609-19. https://doi.org/ 10.1111/odi.12428.

3. Dye BA. The global burden of oral disease: research and public health significance. J Dent Res. 2017;96:361-3. https://doi.org/10.1177/00220 34517693567.

4. World Health Organization. What is the burden of oral disease? https:// www.who.int/oral_health/disease_burden/global/en/.

5. Lang NP, Schätzle MA, Löe H. Gingivitis as a risk factor in periodontal disease. J Clin Periodontol. 2009;36(Suppl 10):3-8. https://doi.org/10.1111/j. 1600-051X.2009.01415.x.

6. Pihlstrom BL, Michalowicz BS, Johnson NW. Periodontal diseases. Lancet. 2005;366:1809-20. https://doi.org/10.1016/S0140-6736(05)67728-8.

7. LiY, Jacox LA, Little SH, Ko C-C. Orthodontic tooth movement: the biology and clinical implications. Kaohsiung J Med Sci. 2018;34:207-14. https://doi.org/10.1016/j.kjms.2018.01.007.

8. Garcia RI, Henshaw MM, Krall EA. Relationship between periodontal disease and systemic health. Periodontol. 2000;2001(25):21-36. https:// doi.org/10.1034/j.1600-0757.2001.22250103.x.

9. Krishnan V, Davidovitch Z, editors. Biological mechanisms of tooth movement. 2nd ed. New York: Wiley; 2015.

10. Meikle MC. The tissue, cellular, and molecular regulation of orthodontic tooth movement: 100 years after Carl Sandstedt. Eur J Orthod. 2006;28:221-40. https://doi.org/10.1093/ejo/cjl001.

11. Saffar JL, Lasfargues JJ, Cherruau M. Alveolar bone and the alveolar process: the socket that is never stable. Periodontol. 2000;1997(13):76-90. https://doi.org/10.1111/j.1600-0757.1997.tb00096.x.

12. Ono T, Hayashi M, Sasaki F, Nakashima T. RANKL biology: bone metabolism, the immune system, and beyond. Inflamm Regen. 2020;40:1-16. https://doi.org/10.1186/s41232-019-0111-3.

13. Yamaguchi M. RANK/RANKL/OPG during orthodontic tooth movement Orthod Craniofac Res. 2009;12:113-9. https://doi.org/10.1111/j.16016343.2009.01444.x.

14. Bollen A-M, Cunha-Cruz J, Bakko DW, Huang GJ, Hujoel PP. The effects of orthodontic therapy on periodontal health: a systematic review of controlled evidence. J Am Dent Assoc. 2008;139:413-22. https://doi.org/ 10.14219/jada.archive.2008.0184.

15. Kirschneck C, Fanghänel J, Wahlmann U, Wolf M, Roldán JC, Proff P. Interactive effects of periodontitis and orthodontic tooth movement on dental root resorption, tooth movement velocity and alveolar bone loss in a rat model. Ann Anat. 2017;210:32-43. https://doi.org/10.1016/j.aanat. 2016.10.004.

16. Meyle J, Chapple I. Molecular aspects of the pathogenesis of periodontitis. Periodontol. 2000;2015(69):7-17. https://doi.org/10.1111/prd.12104.

17. Ristoska S, Dzipunova B, Stefanovska E, Rendzova V, Radojkova-Nikolovska V, Evrosimovska B. Orthodontic treatment of a periodontally-affected adult patient (case report). Open Access Maced J Med Sci. 2019;7:2343-9. https://doi.org/10.3889/oamjms.2019.629.

18. Sun Y, Shu R, Li C-L, Zhang M-Z. Gram-negative periodontal bacteria induce the activation of Toll-like receptors 2 and 4 , and cytokine production in human periodontal ligament cells. J Periodontol. 2010;81:1488-96. https://doi.org/10.1902/jop.2010.100004

19. Chapple ILC, Matthews JB. The role of reactive oxygen and antioxidant species in periodontal tissue destruction. Periodontol.
2000;2007(43):160-232. https://doi.org/10.1111/j.1600-0757.2006. 00178.x.

20. Jantsch J, Schatz V, Friedrich D, Schröder A, Kopp C, Siegert I, et al. Cutaneous $\mathrm{Na}+$ storage strengthens the antimicrobial barrier function of the skin and boosts macrophage-driven host defense. Cell Metab. 2015;21:493-501. https://doi.org/10.1016/j.cmet.2015.02.003.

21. Kitase Y, Yokozeki M, Fujihara S, Izawa T, Kuroda S, Tanimoto K, et al. Analysis of gene expression profiles in human periodontal ligament cells under hypoxia: the protective effect of CC chemokine ligand 2 to oxygen shortage. Arch Oral Biol. 2009;54:618-24. https://doi.org/10.1016/j.archo ralbio.2009.03.010.

22. Park HS, Jung HY, Park EY, Kim J, Lee WJ, Bae YS. Cutting edge: direct interaction of TLR4 with NAD(P)H oxidase 4 isozyme is essential for lipopolysaccharide-induced production of reactive oxygen species and activation of NF-kappa B. J Immunol. 2004;173:3589-93. https://doi.org/ 10.4049/jimmunol.173.6.3589.

23. Kirschneck C, Batschkus S, Proff P, Köstler J, Spanier G, Schröder A. Valid gene expression normalization by RT-qPCR in studies on hPDL fibroblasts with focus on orthodontic tooth movement and periodontitis. Sci Rep. 2017:7:14751. https://doi.org/10.1038/s41598-017-15281-0.

24. Schröder A, Bauer K, Spanier G, Proff P, Wolf M, Kirschneck C. Expression kinetics of human periodontal ligament fibroblasts in the early phases of orthodontic tooth movement. J Orofac Orthop. 2018;79:337-51. https:// doi.org/10.1007/s00056-018-0145-1.

25. Nazet U, Schröder A, Spanier G, Wolf M, Proff P, Kirschneck C. Simplified method for applying static isotropic tensile strain in cell culture experiments with identification of valid RT-qPCR reference genes for PDL fibroblasts. Eur J Orthod. 2019. https://doi.org/10.1093/ejo/cjz052.

26. Livak KJ, Schmittgen TD. Analysis of relative gene expression data using real-time quantitative PCR and the 2(-Delta Delta C(T)) Method. Methods. 2001:25:402-8. https://doi.org/10.1006/meth.2001.1262.

27. Wolf M, Lossdörfer S, Marciniak J, Römer P, Kirschneck C, Craveiro R, et al. CD8+ T cells mediate the regenerative PTH effect in $\mathrm{hPDL}$ cells via Wnt10b signaling. Innate Immun. 2016;22:674-81. https://doi.org/10. $1177 / 1753425916669417$

28. Nanci A, Bosshardt DD. Structure of periodontal tissues in health and disease. Periodontol. 2000;2006(40):11-28. https://doi.org/10.1111/j.1600$0757.2005 .00141 x$

29. Huang H, Williams RC, Kyrkanides S. Accelerated orthodontic tooth movement: molecular mechanisms. Am J Orthod Dentofacial Orthop. 2014;146:620-32. https://doi.org/10.1016/j.ajodo.2014.07.007.

30. Alhashimi N, Frithiof L, Brudvik P, Bakhiet M. Orthodontic tooth movement and de novo synthesis of proinflammatory cytokines. Am J Orthod Dentofac Orthop. 2001;119:307-12. https://doi.org/10.1067/mod.2001. 110809.

31. Kanzaki H, Chiba M, Shimizu Y, Mitani H. Periodontal ligament cells under mechanical stress induce osteoclastogenesis by receptor activator of nuclear factor kappaB ligand up-regulation via prostaglandin E2 synthesis. J Bone Miner Res. 2002;17:210-20. https://doi.org/10.1359/jbmr.2002. 17.2.210.

32. Kirschneck C, Küchler EC, Wolf M, Spanier G, Proff P, Schröder A. Effects of the highly COX-2-selective analgesic NSAID etoricoxib on human periodontal ligament fibroblasts during compressive orthodontic mechanical strain. Mediators Inflamm. 2019;2019:2514956. https://doi.org/10.1155/ 2019/2514956.

33. Schröder A, Küchler EC, Omori M, Spanier G, Proff P, Kirschneck C. Effects of ethanol on human periodontal ligament fibroblasts subjected to static compressive force. Alcohol. 2019;77:59-70. https://doi.org/10.1016/j. alcohol.2018.10.004.

34. Kohli SS, Kohli VS. Role of RANKL-RANK/osteoprotegerin molecular complex in bone remodeling and its immunopathologic implications. Indian J Endocrinol Metab. 2011;15:175-81. https://doi.org/10.4103/2230-8210. 83401.

35. Römer P, Köstler J, Koretsi V , Proff P. Endotoxins potentiate COX-2 and RANKL expression in compressed PDL cells. Clin Oral Investig 2013;17:2041-8. https://doi.org/10.1007/s00784-013-0928-0.

36. Proff $P$, Reicheneder C, Faltermeier A, Kubein-Meesenburg D, Römer P. Effects of mechanical and bacterial stressors on cytokine and growthfactor expression in periodontal ligament cells. J Orofac Orthop. 2014;75:191-202. https://doi.org/10.1007/s00056-014-0212-1. 
37. Uematsu S, Mogi M, Deguchi T. Interleukin (IL)-1 beta, IL-6, tumor necrosis factor-alpha, epidermal growth factor, and beta 2-microglobulin levels are elevated in gingival crevicular fluid during human orthodontic tooth movement. J Dent Res. 1996;75:562-7. https://doi.org/10.1177/00220 345960750010801.

38. Garlet TP, Coelho U, Silva JS, Garlet GP. Cytokine expression pattern in compression and tension sides of the periodontal ligament during orthodontic tooth movement in humans. Eur J Oral Sci. 2007;115:355-62. https://doi.org/10.1111/j.1600-0722.2007.00469.x.

39. Andrade I, Silva TA, Silva GAB, Teixeira AL, Teixeira MM. The role of tumor necrosis factor receptor type 1 in orthodontic tooth movement. J Dent Res. 2007;86:1089-94. https://doi.org/10.1177/154405910708601113.

40. Schröder A, Käppler P, Nazet U, Jantsch J, Proff P, Cieplik F, et al. Effects of compressive and tensile strain on macrophages during simulated orthodontic tooth movement. Mediators Inflamm. 2020;2020:2814015. https:// doi.org/10.1155/2020/2814015.

41. Ren Y, Vissink A. Cytokines in crevicular fluid and orthodontic tooth movement. Eur J Oral Sci. 2008;1 16:89-97. https://doi.org/10.1111/j.1600-0722. 2007.00511.x.

42. Nishijima Y, Yamaguchi M, Kojima T, Aihara N, Nakajima R, Kasai K. Levels of RANKL and OPG in gingival crevicular fluid during orthodontic tooth movement and effect of compression force on releases from periodontal ligament cells in vitro. Orthod Craniofac Res. 2006;9:63-70. https://doi. org/10.1111/j.1601-6343.2006.00340.x.

43. Schröder A, Gubernator J, Nazet U, Spanier G, Jantsch J, Proff P, Kirschneck $C$. Effects of sodium chloride on the gene expression profile of periodontal ligament fibroblasts during tensile strain. J Orofac Orthop. 2020;81:360-70. https://doi.org/10.1007/s00056-020-00232-8.

44. Nazet U, Feulner L, Muschter D, Neubert P, Schatz V, Grässel S, et al. Mechanical stress induce PG-E2 in murine synovial fibroblasts originating from the temporomandibular joint. Cells. 2021. https://doi.org/10.3390/ cells10020298.

45. Baloul SS. Osteoclastogenesis and osteogenesis during tooth movement. Front Oral Biol. 2016;18:75-9. https://doi.org/10.1159/000351901.

46. van't Hof RJ, Armour KJ, Smith LM, Armour KE, Wei XQ, Liew FY, Ralston $\mathrm{SH}$. Requirement of the inducible nitric oxide synthase pathway for IL-1-induced osteoclastic bone resorption. Proc Natl Acad Sci U S A. 2000;97:7993-8. https://doi.org/10.1073/pnas.130511497.
47. Bast A, Kubis H, Holtfreter B, Ribback S, Martin H, Schreiner HC, et al. $\mathrm{NADPH}$ oxidase contributes to resistance against aggregatibacter actinomycetemcomitans-induced periodontitis in mice. Infect Immun. 2017. https://doi.org/10.1128/IAI.00849-16.

48. Alayan J, Ivanovski S, Gemmell E, Ford P, Hamlet S, Farah CS. Deficiency of iNOS contributes to Porphyromonas gingivalis-induced tissue damage. Oral Microbiol Immunol. 2006;21:360-5. https://doi.org/10.1111/j.1399302X.2006.00304.x.

49. Herrera BS, Martins-Porto R, Maia-Dantas A, Campi P, Spolidorio LC, Costa SKP, et al. iNOS-derived nitric oxide stimulates osteoclast activity and alveolar bone loss in ligature-induced periodontitis in rats. J Periodontol. 2011;82:1608-15. https://doi.org/10.1902/jop.2011.100768.

50. Kanzaki H, Wada S, Narimiya T, Yamaguchi Y, Katsumata Y, Itohiya K, et al. Pathways that regulate ROS scavenging enzymes, and their role in defense against tissue destruction in periodontitis. Front Physiol. 2017;8:351. https://doi.org/10.3389/fphys.2017.00351.

51. Tóthová L, Celec P. Oxidative stress and antioxidants in the diagnosis and therapy of periodontitis. Front Physiol. 2017;8:1055. https://doi.org/10. 3389/fphys.2017.01055.

52. Chen M, Cai W, Zhao S, Shi L, Chen Y, Li X, et al. Oxidative stress-related biomarkers in saliva and gingival crevicular fluid associated with chronic periodontitis: a systematic review and meta-analysis. J Clin Periodontol. 2019;46:608-22. https://doi.org/10.1111/jcpe.13112.

53. Kovac $V$, Poljsak B, Perinetti G, Primozic J. Systemic level of oxidative stress during orthodontic treatment with fixed appliances. Biomed Res Int. 2019;2019:5063565. https://doi.org/10.1155/2019/5063565.

54. Nguyen TT. Oxidative stress induced by Porphyromonas gingivalis lysate and nicotine in human periodontal ligament fibroblasts. Odontology. 2018. https://doi.org/10.1007/s10266-018-0374-1.

55. Sies H. Oxidative stress: oxidants and antioxidants. Exp Physiol. 1997;82:291-5. https://doi.org/10.1113/expphysiol.1997.sp004024.

\section{Publisher's Note}

Springer Nature remains neutral with regard to jurisdictional claims in published maps and institutional affiliations.
Ready to submit your research? Choose BMC and benefit from:

- fast, convenient online submission

- thorough peer review by experienced researchers in your field

- rapid publication on acceptance

- support for research data, including large and complex data types

- gold Open Access which fosters wider collaboration and increased citations

- maximum visibility for your research: over $100 \mathrm{M}$ website views per year

At BMC, research is always in progress.

Learn more biomedcentral.com/submissions 